\title{
EL CONFLICTO DE LA CULTURA MODERNA $^{1}$
}

\section{Georg Simmel}

Mientras que la vida ha progresado desde el nivel meramente animal hasta el del espíritu y éste, por su parte, hasta el nivel de la cultura, en ella aparece una contradicción interna, cuyo desarrollo, despliegue y nuevo surgimiento constituye la totalidad de la cultura. Podemos hablar claramente de cultura cuando el movimiento creador de la vida engendra ciertas estructuras en las que encuentran expresión, en concreto, las formas de su consumación y manifestación. Estas formas comprenden, en sí, el fluir de la vida dotándola de contenido y forma, libertad y orden: así, por ejemplo, las obras de arte, las religiones, los conocimientos científicos, las leyes de la técnica y de la sociedad y muchos otros casos. Sin embargo, estos productos de los procesos de la vida disponen, en el instante de su surgimiento, de una existencia propia que poco tiene que ver con el ritmo agitado de la vida, su ascenso y descenso, su continuada renovación, sus permanentes divisiones y reunificaciones. Son armazones donde se solidifica el potencial creativo de la vida; sin embargo, ésta pronto los trasciende. Almacenan la vida imitativa para la que, en el análisis final, no hay espacio que sobre. Muestran una lógica y regularidad propias, un sentido y una fuerza de resistencia específicos, una cierta rigidez e independencia

${ }^{1}$ G. Simmel, «Die Konflikt der modernen Kultur», 1918, Duncker y Humblot, Berlín, traducción realizada a partir del mismo texto incluido en Das individuele Gesetz, Frankfurt, Suhrkamp, 1987, 174-231.

\section{Reis}


muy alejadas de la dinámica espiritual que los creó. En el momento de esta creación corresponden a la vida pero, a medida que tiene lugar su desarrollo continuado, se mantienen en una exterioridad consolidada, algo que los hace independientes.

Aquí se encuentra el fundamento último de que la cultura tenga una historia. Cuando la vida devenida espiritual engendra incesantemente formas que encierran una pretensión de autoclausura, duración y atemporalidad, estas formas son inseparables de la vida, como la condición necesaria sin las que no puede manifestarse, sin las que no puede ser vida espiritual. La vida es un devenir incesante, su ritmo agitado se presentifica en toda nueva estructura en la que se produce una nueva forma de ser, se opone a la duración firme o a la validez atemporal. Cada forma cultural, una vez creada, es minada por las fuerzas de la vida. Tan pronto como una forma ha accedido a un desarrollo insuperable, comienza a revelarse la siguiente forma; ésta, tras una lucha que puede ser más o menos prolongada, triunfará inevitablemente sobre su predecesora.

La historia, como ciencia empírica, vierte su interés hacia el cambio de las formas culturales. Aspira a localizar los portadores concretos y las causas del cambio en cada caso. Pero lo que acaece, en el fondo, es que la vida sólo puede manifestarse a sí misma bajo formas particulares; dispuesta sobre su propia agitación, fluencia y desarrollo, la vida permanentemente se enfrenta a sus propios productos, los cuales han cristalizado y no pueden moverse con ella; pero como su propia existencia externa no puede ser otra, de esta suerte este proceso se hace visible y apalabrable en cuanto desplazamiento de la vieja forma en favor de una nueva. El cambio permanente de los contenidos culturales, en definitiva, de cada estilo cultural como un todo, es la constatación o, antes bien, el éxito de la fecundidad inextinguible de la vida, pero también de la profunda contradicción entre el flujo eterno de la vida y la validez y autenticidad de las formas objetivas en las que inhabita la vida. Ésta se mueve perpetuamente entre muerte y resurgimiento —entre resurgimiento y muerte.

Este carácter del proceso histórico de la cultura ha sido constatado primeramente en el cambio económico. Las fuerzas económicas de cada época despliegan formas de producción que se ajustan a su naturaleza. La economía de esclavos, las constituciones gremialistas, los modos agrarios del trabajo de la tierra — todos ellos, ya formados, expresaban adecuadamente los deseos y las capacidades de su época-. Pero dentro de sus normas y límites surgieron las fuerzas económicas cuya extensión y desarrollo bloquearon el funcionamiento de estos sistemas. Con el paso del tiempo, a través de revoluciones explosivas graduales, reventaron los vínculos opresivos de sus respectivas formas y los reemplazaron por modos de producción más apropiados. Un nuevo modo de producción, sin embargo, no necesita tener una energía arrolladora por sí mismo. La vida misma en su dimensión económica — con su empuje y su afán por avanzar, su metamorfosis y diferenciación — suministra las dinámicas para el movimiento completo. La vida, como tal, carece de forma, si bien sólo se 
fenomeniza en calidad de algo conformado. Tan pronto como cada forma aparece, sin embargo, pretende una validez que trasciende el momento y se emancipa del latido de la vida. Por este motivo la vida está siempre en latente oposición con la forma. Esta oposición pronto se expresa en esta o en aquella otra esfera de nuestro ser y hacer: finalmente esta oposición forma parte de una necesidad total de la cultura en que la vida, sintiendo "la forma como tal» como algo que se ha visto forzada a realizar, socava no sólo esta o esa forma, sino la forma como tal, y la absorbe en su inmediatez, para ponerse ella misma en su lugar, y así dejar correr su propia fuerza y abundancia, tal como mana de su fuente, hasta que todos los conocimientos, valores y formas adquieran validez en cuanto manifestaciones directas de la vida.

Vivimos ahora esta nueva fase de la vieja lucha, que no es la lucha de la actual forma exuberante de vida frente a la vieja carente de vida, sino la lucha de la vida contra la forma, contra el principio de la forma. Moralistas, reaccionarios e individuos con un estilo de vida riguroso tienen razón cuando lamentan la progresiva "carencia de forma» de la vida moderna. No aciertan a comprender, sin embargo, que con ello no sólo tiene lugar algo negativo, la extinción de las formas transmitidas, sino también una reconducción positiva de la vida que socava aquellas formas. Esta lucha, en extensión e intensidad, no permite la concentración de una nueva creación de formas, hace de la necesidad un principio e insiste en luchar contra la forma simplemente porque es forma. Probablemente esto sólo es posible en una época en la que las formas culturales se perciben como un alma exhausta, que ha dado de sí todo cuanto ha podido, mientras aún se encuentra completamente cubierta de los productos de su fecundidad anterior.

Acontecimientos similares tuvieron lugar en el siglo XVIII. Entonces ocurrieron a lo largo de un prolongado período que se extendió desde la Ilustración inglesa del siglo XVII hasta la revolución francesa. Sin embargo, un ideal completamente nuevo inpulsó esta Revolución: la liberación del individuo, la aplicación de la razón a la vida, el desarrollo firme de la humanidad hacia la dicha y la perfección. Nuevas formas culturales se desarrollaron fácilmente en este medio - casi como si hubieran estado predeterminadas de un modo u otro- suministrando seguridad interior a la humanidad. El conflicto de las nuevas formas contra las caducas no generó la tensión cultural que conocemos hoy cuando la vida, por el contrario, se subleva en todos los ámbitos posibles, sobrepasando cualquier forma fija.

Los conceptos de vida, que desde décadas atrás devinieron dominantes en la interpretación filosófica del mundo, prepararon el camino para nuestra situación. De cara a situar este fenómeno dentro del amplio espacio de la historia de las ideas, debo realizar ciertos comentarios. En cada gran época cultural, se puede percibir un concepto central del que se originan los movimientos espirituales y por el que éstos parecen estar orientados. Cada concepto central es modificado, oscurecido y cuestionado de innumerables modos, pero en cualquier caso se mantiene como el «ser oculto» de la época. 
En cada época particular éste se encuentra allí donde el ser supremo, lo absoluto metafísico de la realidad coincide con el valor supremo, con la exigencia absoluta de nosotros y del mundo. Aquí comparecen unas contradicciones lógicas: lo que es incondicionalmente la realidad no requiere ser realizado, no puede decirse del ser incuestionado que debe llegar a ser. Pero las cosmovisiones no se preocupan de esta dificultad conceptual en sus últimas y más elevadas expresiones. Precisamente donde estas últimas se presentan, donde se unen las series opuestas de la existencia y de la obligación ética, uno puede asegurarse la localización de una idea realmente central de la cosmovisión respectiva.

A continuación quiero indicar brevemente ciertos conceptos centrales de otras tantas formas sociales habidas en el discurrir histórico. En el clasicismo griego destacaba la idea del ser, de lo unitario, sustancial, divino. Esta divinidad no fue presentada panteísticamente sin forma, pero fue moldeada dentro de las formas plásticas colmadas de significado. El Medievo cristiano ubicó en su lugar el concepto de Dios en cuanto fuente y fin de la realidad, dueño incondicionado de nuestra existencia que demanda de nosotros libre obediencia y devoción. Desde el Renacimiento, este lugar fue gradualmente ocupado por el concepto de naturaleza. Aparece como el ser y la verdad, como un ideal, como algo que tiene solamente que representarse y lograrse. Al principio esto ocurría entre artistas para los que, de antemano, la unidad del núcleo último de la realidad y de los valores supremos es la condición vital indispensable. El siglo XVII centró su cosmovisión en el concepto de ley natural como la instancia única que define lo esencialmente válido. El siglo de Rousseau construyó la naturaleza como ideal, como valor absoluto, como aspiración y exigencia. Hacia finales de esta época, el yo, la personalidad espiritual, emergió como concepto central. Algunos pensadores representaban la totalidad del ser como creación de un ego; otros veían la identidad personal como cometido, el cometido esencial para el hombre. De hecho, el ego, la individualidad humana, aparecía como una demanda moral absoluta o como propósito metafísico del mundo. A pesar de la diversidad polícroma de sus movimientos espirituales, el siglo XIX no desarrolló un ideal central comprehensivo. En el límite de lo humano se pudo pensar aquí el concepto de sociedad que, para muchos pensadores del siglo XIX, constituía la propia realidad de la vida. De hecho, el individuo era visto frecuentemente como lugar donde se cruzaban las corrientes sociales, o como una ficción o un átomo. Por otra parte, se exigía la emergencia del sí-mismo en la sociedad, el cometido absoluto de sí-mismo como norma absoluta que incluye moralidad y otros aspectos. Sólo a finales de siglo apareció una nueva idea: el concepto de vida accedió a un lugar destacado en el cual las percepciones de la realidad estaban unidas con valores metafísicos, morales y estéticos.

La expansión y desarrollo del concepto de vida queda confirmado por el hecho de que se promocionó, al unísono, por dos filósofos antagonistas, Schopenhauer y Nietzsche. Schopenhauer es el primer filósofo moderno que no se 
pregunta por algún contenido de la vida, por ideas o modos de existencia del ser. De hecho, se pregunta exclusivamente: ¿Qué es la vida? ¿Cuál es su significado puramente como vida? No debe despistar el hecho de que no utilice la expresión "vida», ya que sólo habla de voluntad de vivir o voluntad en general. Más allá de todo su alcance especulativo sobre la vida, la voluntad representa su respuesta respecto a la cuestión sobre el significado de la vida. Esto supone que la vida no puede alcanzar ningún sentido ni fin fuera de ella misma ya que siempre abraza la voluntad, aunque bajo el disfraz de múltiples y variadas formas. Puesto que sólo puede mantenerse dentro de sí misma por su realidad metafísica, puede encontrar únicamente sólo ilusión y desengaño en cada fin aparente. Por otra parte, Nietzsche, que parte de la "vida» como la singular determinación de sí misma, como la sola sustancia de todos sus contenidos, encuentra en la vida misma el propósito de la vida que es negado desde fuera. Esta vida, por su naturaleza, es incremento, derroche y despliegue de completitud y poder, fuerza y belleza que flota sobre sí misma. Adquiere un valor superior, no a través del seguimiento de fines precisos, sino por el desarrollo de sí misma, deviniendo así más vida y logrando un valor que apunta a lo infinito. Aunque la desesperación de Schopenhauer sobre la vida es radicalmente opuesta al júbilo de Nietzsche, debido a contrastes profundos y esenciales de naturaleza distinta a toda decisión o mediación intelectual, estos dos pensadores comparten una visión básica que les hace diferentes del conjunto de los filósofos anteriores. Esta cuestión básica es: ¿Cuál es el significado de la vida, cuál es su valor en cuanto vida? Ellos sólo pueden preguntarse por el conocimiento y la moral, por el yo y por la razón, por el arte y por Dios, por la suerte y por el sufrimiento, después de haber solucionado aquel primer enigma y su solución decide sobre todas esas preguntas. Es sólo el hecho originario de la vida el que suministra significado y medida, valor positivo o negativo. El concepto de vida es el punto de intersección de sendas líneas opuestas de pensamiento que establecen el marco para las decisiones fundamentales de la vida moderna.

Pretendo ahora ilustrar, a través de numerosos ejemplos contemporáneos, la especificidad de la situación cultural que ahora experimentamos (1914) en la que, en particular, predomina la oposición frente al principio de la forma como tal. Nos encontramos esta oposición cuando la conciencia aparece progresando hacia nuevas estructuras. El Medievo tiene sus ideales cristianos y eclesiásticos y el Renacimiento su redescubrimiento de la naturaleza secular. La Ilustración hizo suyo el ideal de la razón y el Idealismo alemán adornó la ciencia con fantasías artísticas y convirtió al arte, mediante el conocimiento científico, en fundamento de lo que es el cosmos. Sin embargo, el impulso básico que está a la base de la cultura contemporánea es negativo y esto porque, a diferencia de los hombres del pasado, nosotros hemos estado durante algún tiempo sin ideal compartido, incluso sin ideales de ningún tipo.

Si se preguntara hoy a los hombres de las capas más instruidas sobre los ideales que mueven sus vidas, la mayoría daría una respuesta especializada deri- 
vada de su experiencia profesional; pero rara vez se escucharía voz alguna en favor de un ideal cultural que pudiera gobernar al conjunto de la humanidad. Existe una buena razón para explicar esto. No sólo hay, por así decirlo, una carencia de material para un ideal cultural unificador, sino que los ámbitos que debería circunscribir son muy numerosos y heterogéneos como para permitir semejante unificación intelectual. Trasladándome a casos concretos, hablaré ahora de fenómenos artísticos.

De las varias tentativas que colectivamente son designadas como Futurismo, parece destacarse sólo el expresionismo como la orientación dotada de una unidad propia. Siendo así el sentido del expresionismo, no me equivoco al afirmar que el movimiento interno del artista, tal y como es vivido, se sigue inmediatamente en la obra o, precisamente, en calidad de obra. Ese movimiento no debe llevar a cabo o moldear una forma que fuera impuesta por sí misma desde el exterior, ya fuera desde lo real o lo ideal. De esta suerte, el expresionismo nada tiene que ver con la imitación del ser o de un suceso, que es intención del impresionismo. Las impresiones, después de todo, no son productos puramente individuales del artista, sino pasivos y dependientes del mundo exterior. La obra de arte que las refleja es un tipo de mezcla de la propia vida del artista y la peculiaridad de un objeto dado. El objeto artístico, en este caso, debe sugerirse al artista desde el exterior, desde la tradición, desde un ejemplo previo, desde un principio fijo. Pero todas estas fuentes de la forma están contenidas en la vida que se afana por desplegarse de forma creativa dentro de sí misma. Si la vida desemboca en semejantes formas, sólo se encuentra doblegada, entumecida y distorsionada en la obra de arte.

Pretendo ahora considerar, en su forma más pura, el modelo expresionista del proceso creador. Los movimientos del alma del pintor, de acuerdo con este modelo, se prolongan, sin más, en la mano que lleva el pincel. La pintura los expresa como un gesto expresa una emoción interna o un grito expresa un dolor; los movimientos del pincel siguen a los del alma sin resistencia. Por lo tanto, la imagen plasmada en el lienzo es el precipitado inmediato de la vida interior, que nada exterior y extraño deja penetrar en su despliegue. Las pinturas expresionistas son visualizadas según algún objeto con el que no tienen ninguna semejanza, y muchos son quienes consideran esto extraño e irracional. Sin embargo, esto no es tan carente de sentido como pudiera parecer de acuerdo a las anteriores preconcepciones artísticas. Aquel movimiento interior del artista que fluye sólo como obra expresionista, puede originarse en las fuentes secretas y desconocidas del alma humana. Pero también puede desencadenarse desde el estímulo de objetos pertenecientes al mundo externo. Hasta fechas muy recientes se mantenía que una respuesta artística productiva debía mostrar una semejanza morfológica con el estímulo que la desencadenaba; de hecho, la escuela impresionista se basaba en su totalidad en esta concepción. El expresionismo se alejó de este presupuesto. Su idea era la de que no hay necesidad de identidad entre la forma de la causa y la de su efecto. De hecho, la percepción de un violín o de un rostro humano puede desencadenar en el pintor respues- 
tas emocionales que, en la transformación promovida por sus energías artísticas, engendra finalmente una forma totalmente diferente. Se puede decir que el artista expresionista sitúa, en el lugar del «modelo», «el motivo» que lanza su vida, obediente en su contenido sólo a sí misma, a un movimiento. Expresado de una manera abstracta, el acto creativo representaba la lucha de la vida por la autoidentidad. Siempre que la vida se expresa a sí misma, desea sólo expresarse a sí misma; de hecho, hace quebrar toda forma que se quiere imponer como realidad o como ley que valen por sí mismas.

La obra pictórica ciertamente tiene forma. Pero con arreglo a la intención del artista, la forma representa sólo una exterioridad inevitable, sólo un mal necesario. Esta forma no tiene, como las formas de todos los otros ideales artísticos, un significado en sí mismo, que sólo se realizaría por el potencial productivo de la vida. Por esta razón, el arte abstracto es indiferente a los estándares tradicionales de belleza y fealdad, los cuales están conectados con la primacía de la forma. La vida, en su flujo permanente, no está determinada por un fin sino impulsada y conducida por una fuerza; por ello, tiene significación más allá de los cánones de belleza y fealdad. Una vez que la obra artística cobra vida, se pone de relieve que no posee ningún tipo de significado y valor que se puede esperar de un dato objetivo independiente de su creador. Este valor, sin embargo, ha sido guardado desde el mismo inicio del acto de pintar — podríamos decir, casi celosamente- por una vida que sólo se da expresión a sí misma. Nuestra peculiar preferencia por las obras del pasado de los grandes artistas podría basarse en este hecho. La vida creativa se ha convertido en soberana en estas obras, de modo tan autosuficiente y enriquecedor que rechaza toda otra forma que es tradicional o compartida con otros. Su expresión en una obra de arte no es sino su destino natural en cada caso. Desde esta perspectiva podría aparecer conexa y plena de sentido como obra de arte, si bien podría aparecer fragmentada, desequilibrada, como si estuviera compuesta de fragmentos, desde el punto de vista de las formas tradicionales. Esto no es un ejemplo de incapacidad senil para producir una forma, no es una debilidad propia de la edad, sino el vigor propio de la edad. El gran artista, en esta época de su perfección, es tan puro que su obra sólo revela, a través de su forma, lo que la corriente latente de su vida produce por sí misma. El único derecho de la forma se ha perdido para el artista.

Ahora sería posible que una forma que se consuma pura como forma y que es, en sí, significativa, pudiera ser la expresión totalmente adecuada de la vida inmediata, ajustándose a ella como una envoltura que ha crecido orgánicamente. Esto es algo indudable en el caso de las grandes obras artísticas que propiamente se deben llamar clásicas. De este modo, se manifiesta una específica relación estructural del mundo espiritual que tiene implicaciones más allá de sus consecuencias para las artes. Podría afirmarse que en el arte se expresa algo que vive más allá de la forma del arte. Todo gran artista y toda gran obra de arte contiene más amplitud y profundidad (surgidas desde la fertilidad de las fuentes más ocultas) de lo que el arte es capaz de expresar. Sin embargo, los 
hombres intentan incesantemente moldear e interpretar esta vida. En los ejemplos clásicos el intento es satisfactorio y la vida se funde completamente con el arte. Sin embargo, la vida alcanza una expresión más altamente diferenciada y más autoconsciente en aquellos casos donde contradice y destruye formas artísticas. Puede recordarse, por ejemplo, el destino interno que Beethoven pretendió expresar en sus últimas composiciones. La vieja forma artística no se rompe sino que es sometida por algo distinto, más amplio, por algo que irrumpe desde otra dimensión.

Algo similar ocurre en el caso de la metafísica. Su pretensión es el conocimiento de la verdad. Pero en ella se expresa algo que permanece más allá del conocimiento y este «más», o "más profundo», o «lo otro», se hace manifiesto por el hecho de que hace violencia a la verdad como tal, porque lo que afirma está lleno de contradicciones y puede ser fácilmente refutado. A las paradojas típicas del espíritu - las que, en verdad, el optimismo cómodo de los superficiales suele pasar por alto- corresponde el hecho de que cierta metafísica, en cuanto símbolo de la vida o relación expresiva de un tipo de hombres con la totalidad del ser, no sea tan verdadera si es verdad como "conocimiento». Tal vez también en la religión se encuentra algo que no es religión, un profundo más allá de sí misma. Cuando este elemento se patentiza, todas las formas religiosas concretas en las que se encuentra la verdadera religión pueden ser destruidas.

En una obra humana, tal vez en toda aquella que surge desde la capacidad creativa del alma humana, hay un «más» que lo que contiene en su forma. Esto distingue todo lo que tiene alma de aquello que es producido de forma mecánica. Aquí, quizás, pudiera encontrarse la motivación para el interés contemporáneo en el arte de Van Gogh. En él, más que en otros pintores, se percibe una vida apasionada que sobrepasa los límites del arte pictórico. Irrumpe desde una amplitud y profundidad muy singulares; el hecho de que encuentre en el talento del pintor un canal para su expresión es algo casual, como si, de igual modo, hubiera podido dar vida también a actividades prácticas, religiosas, poéticas y musicales. Es, ante todo, esta vida palpitante que puede ser sentida en su inmediatez, lo que le hace a Van Gogh tan fascinante.

El hecho de que, por otro lado, una parte de la juventud actual participe del deseo de un arte totalmente abstracto surge de la pasión por una expresión inmediata y desenfrenada de sí misma. El ritmo frenético de la vida de nuestra juventud empuja esta tendencia hasta su extremo absoluto y es joven todo aquello que representa este movimiento. En general, los cambios históricos de un impacto revolucionario interno o externo han sido protagonizados por la juventud. En la naturaleza específica del presente cambio, debemos hacer una particular referencia a esto. Mientras los adultos, debido a su vitalidad disminuida, concentran su atención más y más en los contenidos objetivos de la vida, que en el significado actual podrían ser señalados como sus formas, la juventud se implica más con los procesos de la vida. La juventud sólo desea expresar su poder y su exceso de poder sin hacer caso de los 
objetos implicados. De hecho, el movimiento cultural favorecedor de lo vital y de su expresión contraria a todo lo formal, encarna el significado de la vida joven.

Debe hacerse aquí una observación fundamental que también pueda aplicarse fuera del mundo del arte. ¿Qué cabe decir de la difundida búsqueda de originalidad entre la juventud contemporánea? A menudo es sólo una forma de vanidad, un intento de convertirse en una sensación para sí mismos y para los demás. En los casos excepcionales influye la pasión por expresar realmente la propia vida; la seguridad de que ésta es realmente $s u$ expresión sólo parece darse cuando no es aceptado nada de lo tradicional. Aceptar una forma objetiva supone la pérdida de toda individualidad humana: además, se adulteraría su vitalidad al congelarla dentro del molde de lo ya caduco. Lo que en estos casos hay que salvar no es la individualidad de la vida, sino la vida de la individualidad. La originalidad es, por así decir, sólo la ratio cognoscendi que nos asegura que la vida es pura por sí misma y no las formas que son su expresión, objetivación y solidificación dentro de su fluir. Esto es quizás un motivo subliminal, no explícito pero poderoso, que subyace al moderno individualismo.

Podemos encontrar esta misma voluntad fundamental en uno de los movimientos filosóficos más recientes que se aleja de las expresiones tradicionales de la filosofía. Quiero designarlo como Pragmatismo porque la versión más destacada, la americana, así lo ha denominado. Considero esta línea como la más superficial y limitada. Independientemente de la existencia de cualquier versión establecida, podemos construir un tipo ideal de Pragmatismo que pueda iluminar su relación con la interrogante que nos ocupa. Permítasenos primero entender qué es lo que cuestiona el Pragmatismo. De todos los ámbitos de la cultura, no hay ninguno que nosotros consideramos más independiente de la vida, ninguno tan alejado de los motivos, necesidades y destinos de los individuos que el conocimiento. El hecho de que dos veces dos es igual a cuatro o que las masas se atraen en razón inversa del cuadrado de sus distancias, es válido, lo sepa o no la mente viva, sin hacer caso de los cambios de mentalidad que la humanidad puede sufrir. El conocimiento técnico que está directamente entretejido con la vida y que juega un gran papel en la historia de la humanidad, se mantiene esencialmente intacto en el ascenso y descenso de la vida. El así llamado "conocimiento» práctico, después de todo, es sólo conocimiento «teórico» que ha sido aplicado a objetivos prácticos. Como forma de conocimiento pertenece a un orden con sus propias leyes, un imperio idealizado de la verdad.

Esta independencia de la verdad, que ha sido propuesta en todo momento de la historia, es lo que el Pragmatismo cuestiona. Nuestra vida externa e interna, afirma el Pragmatismo, consiste en representaciones de conocimiento cuya verdad conserva y mejora nuestra vida, cuya falsedad nos lleva a la perdición. Nuestras representaciones están constituidas por influencias puramente psíquicas. En ningún caso son reflejos mecánicos de la realidad en la que se enreda nuestra vida práctica. Por ello sería una coincidencia de todo punto destacable 
que desembocaran en consecuencias deseables y predecibles dentro del ámbito de lo real. Es probable, sin embargo, que entre las numerosas impresiones e ideas que determinan nuestra vida activa, están aquellas que participan del título de verdad porque soportan y mantienen la vida, mientras que otras con consecuencias negativas son llamadas erróneas. No existe, de antemano, una verdad independiente que es posteriormente sumergida en la corriente de la vida para dirigirla de forma correcta, sino al contrario: entre el número infinito de imágenes e ideas que brotan de esta corriente vital y que, de nuevo, influyen, retroactivamente, en su dirección, se encuentran aquellas que corresponden con nuestra voluntad de vivir. Uno podría decir que esto es un accidente; sin este accidente, sin embargo, no podríamos vivir. Son precisamente estas ideas-soporte las que nosotros reconocemos como auténticas y verdaderas. De hecho, ni los objetos por sí mismos, ni la razón soberana, determinan el valor verdadero de nuestros pensamientos. Antes bien, es la vida — que se expresa, a sí misma, a través de necesidades de supervivencia, a veces a través de las necesidades espirituales más profundas - la que nos compele a clasificar nuestras ideas, entre un extremo que nosotros designamos como la verdad completa, y el otro, que definimos como el error más evidente

Aquí no quiero hacer exposición de esta teoría ni criticarla. No problematizo su grado de verdad o falsedad. Simplemente quiero dejar claro que ha sido desarrollada en un tramo particular de la historia. El pragmatismo, como se ha visto, priva a la verdad de su vieja pretensión de ser un dominio libremente suspendido gobernado por leyes independientes e ideales. La verdad ha quedado ahora implicada en la vida, alimentada por sus recursos fecundos, orientada por la totalidad de sus direcciones y objetivos, legitimada por sus valores básicos. La vida, de hecho, ha reclamado su soberanía sobre una provincia previamente autónoma. Esto puede reformularse de la siguiente manera: la forma de la verdad en el pasado suministraba un soporte fijo o un contexto indestructible para el mundo completo de nuestros pensamientos y sentimientos a los que ella pretendía infundir una consistencia interna y un significado autosuficiente. Ahora, sin embargo, pensamiento y sentimiento son seres disueltos en y por el flujo de la vida. Ceden ante fuerzas y direcciones emergentes y cambiantes sin proponer una resistencia basada en un derecho independiente o una validez atemporal. La expresión más pura de la vida como idea central se alcanza cuando es vista como hecho metafísico básico, como la esencia de todo ser. Esto va más allá del problema del conocimiento: ahora todo objeto se convierte en un latido de la vida, una forma de presentarse o un tramo de su desarrollo. En el despliegue completo del mundo hacia el espíritu, la vida asciende como espíritu y desciende como materia. Y cuando esta teoría responde a la cuestión del conocimiento a través de la «intuición», que sobrepasa todas las mediaciones lógicas y racionales, se toma inmediatamente la verdadera interioridad de las cosas, lo cual supone que sólo para la vida es dable entender la vida. Así las cosas, toda objetividad, el objeto de todo conocimiento, debe transformarse en vida, de modo que el proceso de conocimiento, entendido como una función 
de la vida misma, queda confrontado con un objeto al que puede penetrar completamente ya que es igual en cuanto a su esencia. Mientras que el pragmatismo original disolvía la imagen del mundo dentro de la vida desde un punto de vista del sujeto, la filosofía de vida hace esto también para el objeto. Nada se conserva aquí de la forma como principio del mundo fuera de la vida, como una determinación de la existencia con sentido y fuerza propios. Lo que pudiera designarse aquí como forma, aludiría a un acto de misericordia efectuado por la misma vida.

Este movimiento que sobrepasa los principios formales alcanza el culmen no sólo en los pragmatistas, sino en todos aquellos pensadores que han participado del impulso moderno contra los sistemas cerrados. En sociedades del pasado gobernadas por consideraciones clásicas y formales, estos sistemas alcanzaron nivel de santidad. El sistema quiere reunir, por así decir, simétricamente, todos los conocimientos, por lo menos, en sus conceptos más generales, desde un motivo fundamental hasta una construcción proporcionadamente formada por todos los lados de partes superpuestas y subordinadas. En el acabado estético-arquitectónico, en el exitoso redondeado y clausura de este edificio se ve - y esto es un punto decisivo- la prueba para una validez objetiva. Se da la culminación más extrema del principio formal al convertir la perfección interna de la forma en criterio último de la verdad. Ésta es la visión contra la que la vida, que está constantemente creando y destruyendo formas, debe defenderse a sí misma.

La cosmovisión que exalta y glorifica la vida insiste firmemente en dos cosas. De una parte, rechaza al mecanicismo en calidad de principio universal; percibe a éste como una técnica de la vida, quizás como un síntoma de su propia decadencia. De otra parte, hace caso omiso de la pretensión de las ideas de convertirse en ámbito metafísico autónomo, en sustancia de todo ser. La vida no quiere caer bajo el dominio de lo que se encuentra debajo de ella, pero tampoco quiere caer bajo el yugo de la idealidad que se otorga a sí misma el rango más elevado. Aunque ninguna forma suprema de vida es capaz de saber de sí misma sin el gobierno de las ideas, esto ahora parece ser posible porque las ideas mismas derivan de la vida. La esencia de la vida es generar su guía, salvación, oposición, victorias y víctimas. Se sustenta y se impulsa a sí misma, por así decir, por una ruta indirecta, a través de sus propios productos. Aquello que se confronta con ella representa su propio hecho original, expresa el estilo distintivo de la vida. Esta oposición interna es el conflicto trágico de la vida como espíritu, conflicto que se patentiza con más evidencia conforme más autoconsciente deviene la vida.

Visto bajo una perspectiva cultural más general, este movimiento implica la omisión del clasicismo como ideal absoluto para la cultura humana. El clasicismo, después de todo, es la ideología de la forma, que se observa a sí misma como la norma última para la vida y la creación. Nada más satisfactorio y refinado ha tomado el lugar del viejo ideal. El ataque contra el clasicismo no remite a la introducción de nuevas formas culturales. La vida autoconfiada preten- 
de liberarse de la coacción de la forma cuyo representante histórico es el clasicismo.

Quiero dar cuenta, a continuación, de una tendencia idéntica dentro de un ámbito específico de la moral. Con el nombre de «nueva moral» se remite a una crítica de las relaciones sexuales existentes cuya propaganda es impulsada por un pequeño grupo pero de cuyo anhelo participan grupos mucho más extensos. Esta crítica se dirige principalmente contra dos elementos de la escena contemporánea: el matrimonio y la prostitución. Su tema básico puede ser expresado como sigue: el significado más personal e íntimo de la vida erótica es ocultado por las formas en las que nuestra cultura les ha reificado y aprisionado. El matrimonio, concebido desde numerosas consideraciones no-eróticas, va siendo minado desde dentro por cientos de rígidas tradiciones y crueldades legales; donde no es destruido, erosiona toda individualidad y conduce al estancamiento. La prostitución ha devenido prácticamente una institución legal que compele a la vida erótica de la gente joven hacia una dirección deshonrosa que contradice y caricaturiza su naturaleza más íntima. El matrimonio y la prostitución aparecen como formas opresivas que frustran la vida inmediata y genuina. Bajo diferentes circunstancias culturales, estas formas no eran tan inapropiadas. Ahora, sin embargo, concitan contra sí fuerzas que brotan de los últimos recursos de la vida. De forma más evidente que en los otros dominios culturales puede comprobarse aquí lo poco que corresponde, hasta ahora, la nueva formación positiva al motivo fundamental perfectamente positivo de la destrucción de las formas. Ninguna proposición de aquellos reformadores es, en modo alguno, generalmente aceptada como una sustitución suficiente de las formas condenadas por ellos. El cambio cultural típico, es decir, la lucha y la sustitución de la forma envejecida por una nueva que aspira a surgir, está aquí muy atrasado. La fuerza actuante bajo el manto de las nuevas formas está dirigida, temporalmente y sin disfraz, contra las viejas formas vaciadas de una vida erótica genuina. Sin embargo, está incurriendo en la contradicción previamente mencionada ya que la vida erótica, tan pronto como es expresada en los contextos culturales, requiere necesariamente alguna forma. En principio, sólo un observador superficial es quien aquí no ve sino deseo desenfrenado y anárquico, si bien, a través de un análisis profundo, la cosa es distinta. La vida erótica genuina, de hecho, fluye naturalmente por canales individuales. La oposición se dirige contra formas porque éstas la reconducen hacia esquemas generalizados y, con ello, violentan su singuralidad. Aquí se trata de la pugna entre vida y forma que, de modo menos abstracto, menos metafísico, se resuelve como una lucha entre individualidad y generalización.

Podemos encontrar la misma tendencia en la religión contemporánea. Vinculo esto con el hecho observado hace diez o veinte años en el que un reducido número de individuos intelectualmente avanzados emplean el misticismo para satisfacer sus necesidades religiosas. En general, puede aceptarse que éstas se han desarrollado en una de las iglesias existentes. Tras su acercamiento a la 
mística queda por reconocer una doble motivación. Por un lado, que las formas a cuyo través se transforma la vida religiosa en determinadas formas portadoras de contenidos, no les satisfacen; por otro, que, por ello, el deseo no ha sido sacrificado, sino que busca otros fines y otros derroteros. Parece claro que, para dar ese giro hacia la mística, se tiende a suprimir el contorno fijo, la precisión del límite de la vida religiosa. El misticismo aspira a una deidad que trascienda toda forma personal y particular; pretende una expansión indeterminada del sentimiento religioso que no choca con ningún límite dogmático, una profundización en la infinitud sin forma, un modo de expresión basado solamente en el anhelo virtuoso del espíritu. El misticismo aparece como el último refugio de los individuos religiosos que aún no se han desligado de todo asidero trascendente, sino de todo lo determinado y establecido en cuanto a contenidos.

La instancia más decisiva de este desarrollo — aunque pudiera estar repleto de contradicciones y estar eternamente separado de su objetivo- parece afanarse por disolver las formaciones de la fe en la vida religiosa, en la religiosidad, considerada como una disposición funcional del proceso interno de la vida, de la cual aquéllas han surgido y siempre surgen. Hasta hace poco el cambio de la cultura religiosa se consumaba siempre en la forma que aquí se muestra: una cierta forma de vida religiosa, originalmente adecuada en su surgimiento a sus potencias y características esenciales, se petrifica gradualmente al privilegiar los asuntos más superficiales y exteriores. Ésta es desplazada por una nueva forma emergente en la que la dinámica y el impulso religioso laten de nuevo. Es decir, una nueva forma religiosa, una nueva serie de creencias religiosas ocupan el lugar de otras caducas. No obstante, para una gran cantidad de hombres de nuestros días los objetos sobrenaturales de las creencias religiosas han sido radicalmente suprimidos; su impulso religioso, sin embargo, no ha sido con ello eliminado. Su fuerza efectiva, que formalmente se manifestaba a sí misma a través del desarrollo de contenidos dogmáticos más adecuados, no puede expresarse verdaderamente a sí misma por medio de la polaridad de un sujeto creyente y un objeto de creencia. En el estado último de los asuntos hacia los cuales está apuntando esta nueva tendencia, la religión pasaría a ser una función en cuanto medio para la expresión directa de la vida. No sería algo similar a una simple melodía dentro de la sinfonía de la vida, sino una tonalidad a cuyo través ésta se despliega como totalidad. El espacio de la vida, repleto de contenidos seculares, de acciones y destinos, pensamientos y sentimientos, estaría atravesado por esa unidad interna de la humildad y la exaltación, la desazón y la quietud, el riesgo y la consagración, estados que sólo podemos tildar de religiosos. La vida consumida de esta forma demostraría su valor absoluto — valor que, bajo otras circunstancias, le fue dado sólo a ella a través de formas singulares en las que se manifestaba y a través de contenidos individuales de creencia en los que se ha cristalizado-. Angelus Silesius nos da una muestra de ello, cuando separa los valores religiosos de todas las conexiones fijadas con algo específico y reconoce su lugar como vida vivida: 


\section{El santo, cuando bebe complace tanto a Dios como cuando reza y canta}

No se trata de la llamada «religión secular». También ésta se enraiza siempre en contenidos concretos, sólo que son empíricos y no trascendentes; también canaliza la vida religiosa a través de ciertas formas de belleza y grandeza, de sublimidad y conmoción lírica. Aquí, sin embargo, está en cuestión si la religiosidad es un proceso inmediato de la vida que abarca todo latido latente de la existencia: ¿en vez de un tener, es un ser?; ¿se puede tratar de un ser piadoso que, en caso de tener objetos, puede denominársele fe? Ahora, sin embargo, la religiosidad es similar a la vida misma. No apunta a la satisfacción de necesidades eternas, sino que busca la corriente continua de la vida en una esfera profunda en la que aún no se ha escindido en necesidades y satisfacciones. En esta esfera de perfección religiosa no se requiere un objeto que prescriba una forma determinada - como un pintor expresionista tampoco libera su necesidad artística ajustándose a un objeto exterior- La vida aspira a expresarse directamente como religión y no en un lenguaje con un léxico dado y una sintaxis prescrita. Podría decirse de forma aparentemente paradójica: el espíritu quiere mantener su fe aun cuando haya perdido su fe en contenidos concretos y predeterminados.

Esta dirección de las almas religiosas, que a menudo se deja sentir en los propósitos, en cierta extraña confusión y en una crítica puramente negativa que mal se comprende a sí misma, ahora encuentra la más profunda dificultad: la vida puede expresarse y realizar su libertad sólo a través de formas; si bien éstas deben, necesariamente, sofocar la vida y obstruir la libertad. La religiosidad, la fe es un estado del alma que es dado con la vida misma y a la que colocaría también de determinado modo, si a aquel estado jamás le fuese dado un objeto religioso — al igual que una naturaleza erótica debería mantener y acreditar su carácter aunque jamás pudiera encontrar un individuo digno de ser amado por ella-. Sin embargo, se puede dudar de si la voluntad de una vida religiosa no necesita un objeto, si un carácter meramente funcional, sin forma en sí, que solamente matiza lo más elevado y bajo de la vida — que parece representar el sentido significativo de numerosos movimientos religiosos-, puede realmente satisfacerla. Posiblemente esta nueva religiosidad es un intermedio casual. Puede tenerse entre las dificultades internas que más acucian a un buen número de miembros de la sociedad moderna el hecho de que es imposible proteger a las religiones con sus iglesias tradicionales, al mismo tiempo que la dinámica religiosa, a pesar del incremento de la Ilustración, persista. Esto es así ya que a la religión le pueden haber sido arrebatados sus ropajes pero no su vida. Hay una salida a este dilema en el cultivo de la vida religiosa como una cosa en sí misma: la transformación del verbo «creer» de un transitivo "yo creo que» a un puramente intransitivo "yo creo». A la larga, tal vez, esto puede convertirse en una contradicción no menor. Aquí de nuevo 
vemos el conflicto básico inherente a la naturaleza de la vida cultural. La vida debe realizarse como forma o proceder a través de formas. Pero las formas pertenecen a un orden de ser completamente diferente. Requieren algunos contenidos que se sitúan más allá de la vida. De esta suerte, asoma la contradicción en la esencia misma de la vida, sus dinámicas oscilantes, sus destinos temporales, la diferenciación incesante de cada uno de sus momentos. La vida conlleva, en sí misma, la contradicción. Sólo puede entrar a formar parte de la realidad bajo la forma de su antítesis, esto es, sólo bajo la forma de la forma. Esta contradicción es más pronunciada y aparece más irreconciliable en la medida en que la vida se hace a sí misma ${ }^{2}$. Las formas mismas, sin embargo, niegan esta contradicción en sus rígidas configuraciones individuales, en la exigencia de sus derechos imprescriptibles, se presentan a sí mismas como el verdadero significado y valor de su existencia. En la medida en que la cultura se ha desarrollado, semejante contradicción se acentúa en grado sumo.

La vida anhela lograr algo que no puede alcanzar. Desea trascender las formas y aparecer en su desnuda inmediatez. Los procesos de pensar, desear y conformar sólo pueden sustituir una forma por otra. Nunca pueden reemplazar la forma como tal por la vida que, como tal, trasciende la forma. Todos estos ataques contra las formas de nuestra cultura, que alinean contra ellas las fuerzas de la vida en "sí misma», encarnan las contradicciones internas más profundas del espíritu. Aunque este conflicto crónico entre forma y vida ha sido más acusado en otras épocas históricas, ninguna tanto como la nuestra la ha revelado como su auténtico tema de controversia.

Es un prejuicio filisteo pensar que todos los conflictos y problemas existen para ser resueltos. Ambos tienen cometidos adicionales en la economía e historia de la vida, cometidos que ellos satisfacen con independencia de sus propias soluciones. De hecho, existen con derecho propio, aun cuando el futuro no reemplace los conflictos por sus soluciones, sino solamente sus formas y contenidos por otros. Pues, realmente, todos aquellos fenómenos problemáticos, ya discutidos, nos hacen conscientes cuán contradictorio es el presente para que nos detengamos en él, en qué medida apunta, sin duda, a una transformación más fundamental que la que sólo se refiriese al cambio de una forma existente por una nueva que aspira a surgir. Porque casi nunca, en el último caso, el puente entre el antes y el después de las formas culturales apareció tan completamente destruido como ahora, de modo que la vida sin forma en sí sólo parece quedar suspensa en el vacío. Indudablemente, la vida también empuja hacia aquel cambio típico cultural, hacia la creación de nuevas formas, adecuadas a

2 Como la vida es la antítesis de la forma, y como aquello que es conformado sólo puede describirse conceptualmente, el concepto de vida no puede liberarse de cierta imprecisión lógica. La esencia de la vida sería negada si uno intentara construir una definición conceptualmente exhaustiva. El paso de la vida consciente hacia su total auto-consciencia, no podría hacerse sin conceptos; los conceptos son esenciales para la auto-conciencia. El hecho de que las posibilidades de expresión quedan muy limitadas por la propia esencia de la vida, no disminuye la claridad de aquel antagonismo intuitivo del mundo. 
las fuerzas actuales, aunque con éstas — tal vez haciéndose, la vida, lentamente consciente, prolongando por más tiempo la lucha abierta - un problema sólo es suplantado por uno nuevo, un conflicto por otro. Pero con esto se realiza el verdadero modelo de la vida que, en sentido absoluto, es una lucha que abarca la relativa oposición de lucha y paz, mientras la paz absoluta, que quizá también encierra esta oposición, continúa siendo el secreto divino.

(Traducción de Celso SÁnChez CAPDEQuí.) 


\section{CRÍTICA DE LIBROS}

